\title{
Diurnal Activity and Sexual Maturation of the South American Fruit Fly (Diptera: Tephritidae) in the Laboratory
}

\author{
Ivanildo S. Lima ${ }^{1}$ and Philip E. Howse ${ }^{2}$ \\ ${ }^{1}$ FIT/CECA/UFAL, Laboratório de Ecologia Química, BR 104 Norte, \\ Km 14, 57072-970, Maceió, AL. \\ ${ }^{2}$ Department of Biology, University of Southampton, Bassett Crescent \\ East, Southampton SO16 7PX, U.K.
}

An. Soc. Entomol. Brasil 26(2): 299-308 (1997)

Atividades Diárias e Maturação Sexual da Mosca-das-frutas Sul Americana

(Diptera: Tephritidae) em Laboratório

\begin{abstract}
RESUMO - As atividades de locomoção e de limpeza em moscas adultas de Anastrepha fraterculus (Wiedemann) (Diptera: Tephritidae) ocorreram durante todo o período fotofásico. Moscas acasaladas alimentaram-se mais do que moscas vírgens. Em oviposição, as fêmeas mostraram territorialidade e apenas as acasaladas ovipositaram. Os machos começaram a mostrar comportamento de chamamento com 5 dias de idade, alcançando a maturidade sexual completa aos 10 dias. Cerca de 54\% das fêmeas vírgens e sexualmente maduras, copularam no mesmo dia em que foram colocadas juntas com machos vírgens da mesma idade. Fêmeas de A. fraterculus necessitaram de pelo menos $30 \mathrm{~min}$ de acasalamento para suprir as espermatecas com esperma, e a eficiência na transferência de esperma por ocasião do primeiro acasalamento foi de $100 \%$.
\end{abstract}

PALAVRAS-CHAVE: Insecta, Anastrepha fraterculus, comportamento, interações entre adultos, transferência de esperma.

ABSTRACT - Locomotion and grooming in immature adult Anastrepha fraterculus (Wiedemann) (Diptera: Tephritidae) occurred throughout the daylight period. Feeding seemed to be slightly higher in mated than in unmated flies. Ovipositing females showed territoriality and only mated females laid eggs. Males started to display courtship behavior at 5 days old, reaching the complete sexual maturation at day 10 . About $54 \%$ of the virgin mature females copulated on the day they were paired with virgin males of the same age. Female $A$. fraterculus seemed to require more than $30 \mathrm{~min}$ of mating to supply all spermathecae with sperm, and the efficiency of sperm transference after first mating was $100 \%$.

KEY WORDS: Insecta, Anastrepha fraterculus, behavior, adult interactions, sperm transference.

A knowledge of behavioral sequences (i.e., feeding, mating, oviposition and resting) in frugivorous tephritid is important for the development of efficient control mechanisms. In the genus Anastrepha, such sequences are known only for a few species: A. fraterculus 
(Wiedemann), A. ludens (Loew), A. sus- pensa (Loew), A. obliqua (Macquart), A. striata (Schiner), and A. serpentina (Wiedemann) (Baker et al. 1944, Dodson 1982, Aluja et al. 1983, Burk 1983, Malavasi et al. 1983, Aluja et al. 1989, Aluja \& Birke 1993). Tephritid fruit flies generally have a polygynous mating system (Prokopy \& Roitberg 1984) in which environmental or behavioral conditions determine clumping of females after which males are then able to have exclusive control of those females. Aluja et al. (1993) reported that in the genus Anastrepha there are cases of "true lekking" (e.g., A. obliqua) and "nonlekking" (A. bistrigata Bezzi). In the first case males aggregate on a plant for the purpose of calling activity, and approaching females select their mate, whereas in a non-lekking strategy, females are usually forced to mate with males which are calling in isolation (Morgante et al. 1993). Malavasi et al. (1983) reported that, at dawn, adult $A$. fraterculus were resting on the under surface of leaves, and male calling activity in small leks began at 07:00 $\mathrm{h}$ and ceased before 11:00 h. Feeding and oviposition occurred throughout the day and ended before 18:00 h. However, the activity patterns of immature flies have not been described.

Temperature, along with the photoperiod, is considered as one of the most important abiotic factors influencing insect development and behavior. In the laboratory, the photoperiod has no direct influence on the life cycle of A. fraterculus, whereas temperatures between 25 and $30^{\circ} \mathrm{C}$ were the best for oviposition, larval development, pupation, and adult emergence (Salles 1993a). In the field, the highest percentage of adults of both sexes caught in McPhail traps (using peach juice as attractant) occurred between 15:00 h and 19:00 h (Salles 1993b). This finding suggests that adult $A$. fraterculus search for food mainly in the afternoon and that temperature and light intensity may play an important role in the circadian activities of the flies.

This paper reports on the activities of immature and mature flies A. fraterculus, and the process of male and female sexual matu- ration and courtship behavior. Short-range interactions between both sexes during the courtship, and the efficiency of sperm transference after first mating were also quantified.

\section{Material and Methods}

Insects. The culture of $A$. fraterculus was established as pupae from CPACT/ EMBRAPA, southern Brazil. Experimental flies were randomly selected from the 2 nd generation obtained in the insectary at the University of Southampton (i.e., laboratoryreared flies of 3 rd generation). The rearing and the experimental room were maintained at $26 \pm 2^{\circ} \mathrm{C}, 60 \pm 10 \% \mathrm{RH}$ and $13: 11 \mathrm{~h} \mathrm{LD}$ photoperiod at 1600 lux with a $1 \mathrm{~h} 15$ lux dawn and dusk.

Diurnal Activity of Sexually Immature Flies and Sexual Maturation. For this study, 20 adult flies (10 virgin males and 10 virgin females) of A. fraterculus were transferred to a plastic aquarium cage $(40 \times 25 \times 15 \mathrm{~cm})$, on the day of adult emergence (no copulation occurs during this period). They were supplied with a dry (3:1 mixture of refined sugar and brewers yeast) and a liquid diet (a teaspoon of honey in $100 \mathrm{ml}$ of distilled water). Two artificial fruits (made using water, agar and blackberry juice) wrapped in stretched Parafilm ${ }^{\circledR}$ (Salles 1992) were introduced into the cage to observe whether immature female flies would attempt to oviposit. The artificial fruits were replaced with new ones every two days. Observations were carried out from the 2nd day after adult emergence, to the day when the 1st mating was achieved. The locomotory activity (number of bouts of flying, walking or jumping), feeding (number of flies probing on the liquid or dry food), grooming (number of flies self-cleaning), and oviposition (females inserting their ovipositor into fruit), were recorded over a $5 \mathrm{~min}$ period, at 60 min intervals, starting at dawn and finishing after the 1 st half hour of the dark period. As the male courtship behavior and mating initiation in A. fraterculus occur mainly in the first two hours of the photophase (Morgante 
et al. 1983), observation during this period was increased to $10 \mathrm{~min}$.

\section{Diurnal Activity of Sexually Mature Mated}

Flies. The diurnal activity of the sexually mature mated flies was observed in a group of 20 flies (10 mated males and 10 mated females) aged between 13 and 20 days which were kept in a cage as described above, under the same rearing conditions. Each fly was marked on the thorax (without anaesthesia) with one or two small spots of a non-toxic coloured paint (Lima et al. 1994). Different colours were used to identify each fly individually. Four artificial fruits were offered to the flies. The fruits were checked for eggs and replaced with new ones every two days. The experiment was carried out for 8 consecutive days, and the behaviors observed were feeding, oviposition and calling activity (males rotating their bodies and vibrating the wings), which were recorded for the same time duration and at intervals described above.

\section{Quantifying Short-range Interactions Dur-} ing Courtship Behavior. During courtship behavior of $A$. fraterculus, several short-range interactions between both sexes may occur. Some of these interactions were quantified in groups of 25 virgin male and 25 virgin female flies aged 25 to 30 days. Adult flies were transferred to a plastic aquarium cage $(40 \mathrm{x}$ $25 \times 15 \mathrm{~cm}$ ) one day before the experiment, and supplied with food and water. The interactions observed in this study were: femalefemale contact (number of bouts of a female touching another female with her proboscis), male-male contact (number of bouts of a male touching another male with his proboscis), male-female contact (number of bouts of a male touching a female with his proboscis, or vice versa), copulation attempts between males (number of bouts of a male trying to mount another male), copulation attempts between male and female (number of bouts of a male trying to mount a female), female rejection (number of bouts of a female refusing to copulate), and copulation (number of successful copulation). The observations were recorded over a 2 hour period starting at dawn. The experiment was replicated 4 times and the flies were used only once per replicate.

Efficiency of Sperm Transference After First Mating. Flies used in this experiment were sexed on the day of adult emergence and maintained in plastic cages provided with food and water. When they reached the age of 25 to 35 days they were placed together in another cage where mating took place. Copulating pairs were transferred to small plastic vials to record the duration of mating. Following mating, the females were dissected for examination of spermatozoa in their spermathecae. Depending on the genus, 2 or 3 spermathecae may be found in tephritid fruit fly. Anastrepha spp have three spermathecae, which is a characteristic of higher Diptera (Wigglesworth 1984). The spermathecae were detached from the bursa copulatrix, placed into a droplet of Ringer solution on a slide glass, and crushed by the pressure of a glass coverslip. The presence or absence of sperm was examined under a microscope at $\mathrm{x}$ 380 magnification.

\section{Results}

Diurnal Activity of Sexually Immature Flies. The immature adult flies were observed feeding and grooming throughout the light period and ceased with the onset of darkness (Fig. 1). Locomotory activity was also almost exclusively diurnal. There was a peak in locomotion (mainly walking) at the beginning of the dusk period, when it increased by nearly $54 \%$. Most of the flies remained still, or moved very little in the dark. On artificial fruit, female and male flies were observed either feeding or grooming. Virgin females were neither seen ovipositing nor trying to insert their ovipositors into fruit. Encounters between flies of both sexes resulted in "fights" which lasted fractions of seconds. During these contests, male and female flies often opened their wings at a $90^{\circ}$ angle to the body 


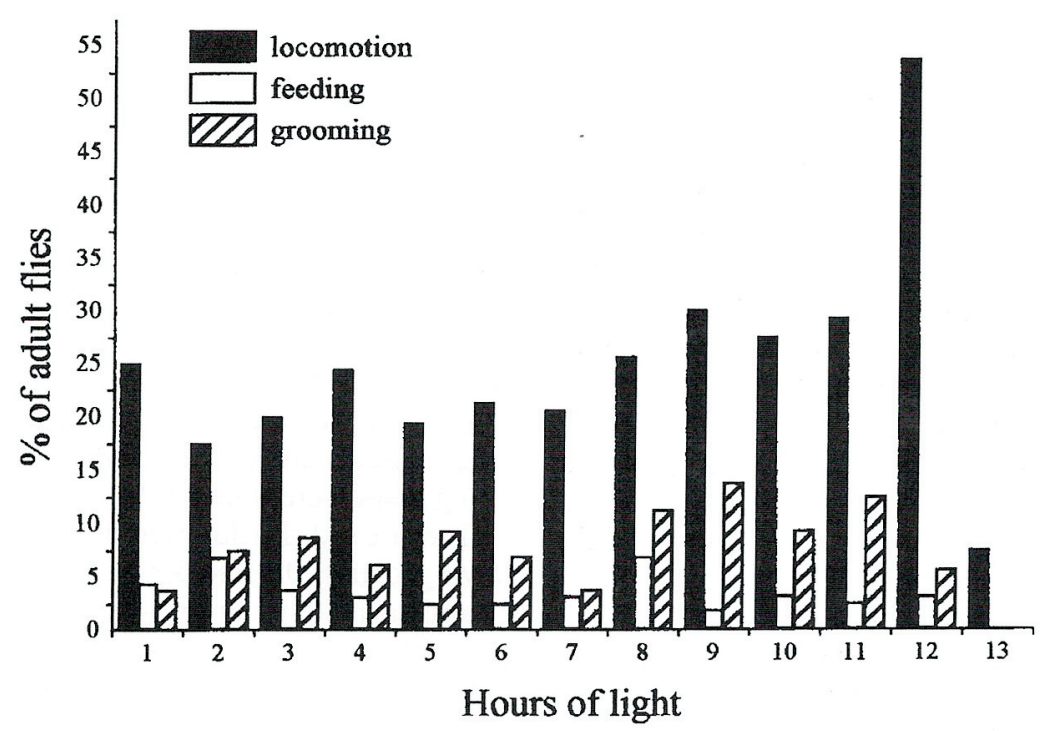

Figure 1. Diurnal activity rhythms of immature flies Anastrepha fraterculus (2 to 10 days old). Each bar represents the mean of nine days of observations. Locomotion was measured by the number of flies walking, flying or jumping; feeding by the number of flies probing on the diet and grooming by the number of flies cleaning themselves (error bars are not shown).

axis and stepped laterally to the left and right, sometimes doing this while facing another male or female fly. The latter was often seen to raise her ovipositor.

Sexual Maturation and Courtship Behavior. Sexual maturation of adult male flies began at the age of 5 days. Males younger than 5 days showed no courtship behavior. At dawn, mature males repeatedly rotated their bodies through $360^{\circ}$ while rapidly fanning their wings. However, they did not try to copulate and did not approach other males or females. This is part of a calling display which ceases after one hour of full light conditions. The duration of male calling activity was increased to nearly four hours when they reached the age of 8-9 days.

Males expanded the abdominal pleural region (segments 3,4 and 5) to form a small pouch on each side of the abdomen and distended a thin membranous pouch of cuticle surrounding the anal area (Fig. 2). In addi- tion, males extended their wings at right angles to the body axis and periodically vibrated them or, alternatively, one wing at a time was raised and lowered, the sequence being repeated with each wing. In this way, wing waving sometimes continued for a period of 1530 seconds with the male relatively stationary. Occasionally, while facing another male in an apparently defensive posture, a male extended its proboscis and contracted its abdomen in the long axis, while the wings were bent downwards and the forelegs were working forwards grooming the proboscis. Males were seen calling either in isolation or in small groups of 3 or 4 , usually at the top of the cage. Females did not produce lateral pouches or vibrate their wings. Males tried to mount each other or approaching females. In many copulation attempts, the female directed down the ovipositor, which prevented the male from copulating. If a calling male persisted in attempting copulation with a non-receptive female, she escaped by falling on the cage floor. 


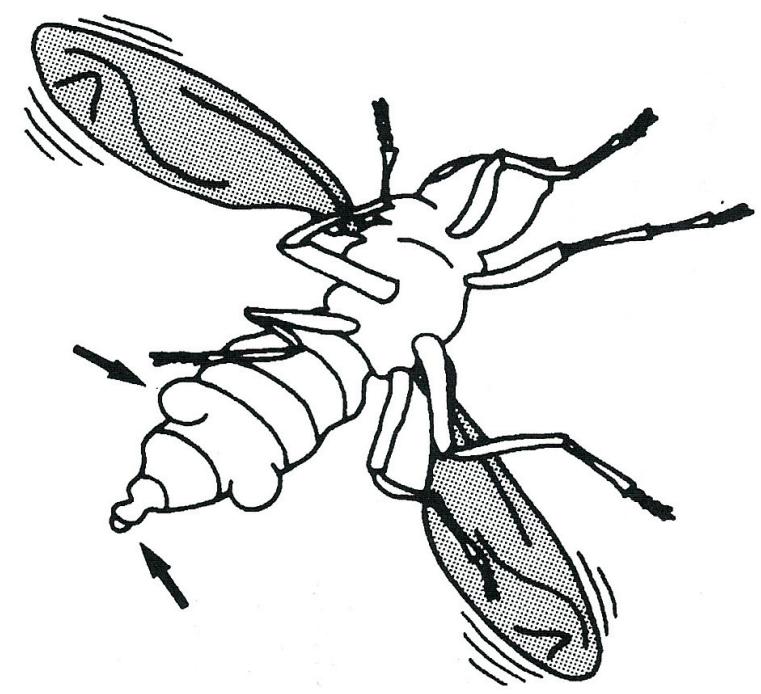

Figure 2. A sexually mature calling male Anastrepha fraterculus. Arrows indicate the lateral abdominal pouches and the everted anal tissue (underside of wing is shown shaded).

If a female advanced and contacted the male with the proboscis, he jumped on to her back and attempted to copulate. Female flies began to copulate at the age of 11 days. During copulation, the bodies of the mating pair were parallel with the male over the female. The male usually moved his proboscis probing the head of the female. The process of separation began with intensive female wing fanning. Following separation, the female began cleaning the ovipositor sheath with her hind legs. $100 \%$ of the males resumed calling activity immediately after copulation, but no males were seen copulating more than once in a single day.

Diurnal Activity of Sexually Mature Mated Flies. During the artificial dawn period, calling activity was observed in $66 \%$ of the males, and it increased to nearly $100 \%$ at the beginning of full light intensity, when most mating initiation occurred and calling males had selected a position in the cage (isolated or in leks). Calling males tried to copulate with approaching male or female. Calling remained at a high level during the next two hours. The percentage of calling males gradually decreased to $86 \%$ after four hours, and to nearly $10 \%$ at six hours. Males were not seen calling after seven hours (Fig. 3). The mean percentage of mated flies observed feeding, was slightly higher than that observed for virgin flies. Feeding occurred mainly during the period between four and eight hours of light conditions. Mated female flies were not observed ovipositing during the dawn period. Females which landed on an artificial fruit at that time of the day, often fed on it. Oviposition started immediately after the beginning of full light conditions, occurred throughout the day, and was observed even in the dusk period. The highest oviposition percentage (28.7\%) was observed five hours into the light period. A female remained ovipositing or probing fruits with the proboscis for several minutes, and repelled any intruder using the proboscis and wings. On the following day, a female which had previously been observed defending a territory on a particular fruit, was often found displaying similar behavior on another fruit. 


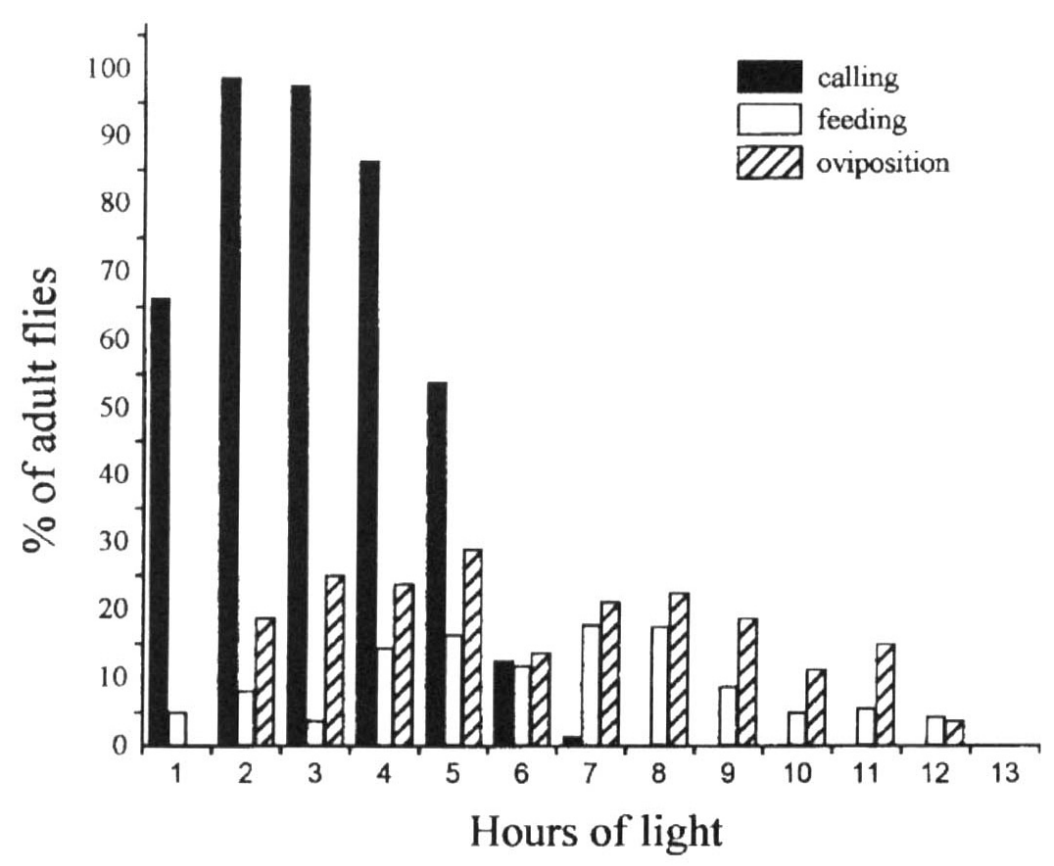

Figure 3. Diurnal activity rhythms of mated flies Anastrepha fraterculus (13 to 20 days old). Each bar represents the mean of eight days of observations. Calling was measured by the number of males displaying wing fanning, body rotation, and inflation of the abdominal pouches. Oviposition was measured by the number of females inserting their ovipositor into fruit. Feeding was measured by the number of flies probing on the diet or on the artificial fruit (error bars are not shown).

Short-Range Interactions During Courtship Behavior. Table 1 shows the mean $( \pm \mathrm{SE})$ number of the various short-range interactions observed during courtship behavior of $A$. fraterculus. A mean of 39.5 female-female contacts was observed over a period of 120 min of light, and it was expressed solely as an aggressive behavior. A female walked towards another (usually stationary) female, before making contact with her proboscis. Contacts between calling males, without trying to copulate each other, were by far more frequent than the interactions between females. Over the same period, a mean of 109 male-male contacts was recorded, and, as it was expected, most of these encounters resulted in fights. After being repelled by the resident male, the intruder always retreated.
The mean number of times that males tried to mount other males was very high, if compared with the mean of copulation attempt with females (20.5 and 24.0, respectively). Malefemale contact, without copulation attempt, was observed 83.5 times, which occasionally resulted in fights or with the opposite sex leaving after being touched. Female rejection was observed 17.0 times, which shows that out of 24 copulation attempt a mean of 13 females will accept the mates. About $54 \%$ of the females (13) copulated on the day on which they were placed in a single cage with a 1:1 sex ratio.

Efficiency of Sperm Transference After First Mating. A total of 40 females were dissected to observe the presence of sperm in 
Table 1. Mean $( \pm \mathrm{SE})$ number of short-range interactions observed during courtship behavior of Anastrepha. fraterculus in the laboratory.

\begin{tabular}{lrrrr}
\hline Interactions $^{1}$ & \multicolumn{4}{c}{ Number of interactions } \\
\cline { 2 - 5 } & \multicolumn{1}{c}{ Light up to } & \multicolumn{1}{c}{ Light 60 to } & \multicolumn{1}{c}{ Light 90 to } & Total \\
& $60 \mathrm{~min}$ & \multicolumn{1}{c}{$90 \mathrm{~min}$} & $120 \mathrm{~min}$ & \\
\hline Female-female contact & $15.5 \pm 1.19$ & $15.5 \pm 1.55$ & $8.5 \pm 1.20$ & $39.5 \pm 1.32$ \\
Male-male contact & $51.7 \pm 1.80$ & $42.7 \pm 7.12$ & $14.5 \pm 1.20$ & $109.0 \pm 4.84$ \\
Male-female contact & $33.0 \pm 1.96$ & $28.7 \pm 5.48$ & $21.7 \pm 2.21$ & $83.5 \pm 1.55$ \\
Copulation attempt (male-male) & $12.2 \pm 0.85$ & $5.5 \pm 0.65$ & $2.7 \pm 0.48$ & $20.5 \pm 1.85$ \\
Copulation attempt (male-female) & $11.7 \pm 1.03$ & $8.5 \pm 1.71$ & $3.7 \pm 0.25$ & $24.0 \pm 1.68$ \\
Female rejection & $8.7 \pm 0.85$ & $4.7 \pm 0.85$ & $3.5 \pm 0.65$ & $17.0 \pm 1.68$ \\
Successful copulation & $9.7 \pm 0.48$ & $2.7 \pm 0.25$ & $0.5 \pm 0.29$ & $13.0 \pm 1.78$ \\
\hline
\end{tabular}

${ }^{1}$ The observations were carried out in a group of 25 virgin male and 25 virgin female flies aged 25 to 30 days and used only once/replicate.

their spermathecae. The relative amount of sperm transferred was not measured, but it was observed that when copulation lasted less than 30 min two out of three spermathecae contained sperm. The results show that the efficiency of sperm transference after first mating in A. fraterculus was $100 \%$. It is suggested that each spermatheca is supplied with spermatozoa separately, and that females require at least 30 min of mating to achieve an optimum load of sperm storage.

\section{Discussion}

In immature adult $A$. fraterculus, locomotion and grooming occurred throughout the daylight period. The highest level of locomotory activity occurred at dusk, and may be associated with the abrupt change of light intensity in the laboratory, which dropped from 1600 lux to nearly 15 lux over a period of one hour. Under these conditions, the flies moved around the cage until they found a suitable resting place. Feeding was observed throughout the day for both mated and unmated flies, but mated flies seemed to consume more food. This finding could be explained by the hypothesis that virgin insects (especially females) consume less food, because they can develop their first batch of oocytes without ingesting material rich in protein (Browne 1993). As they have lower energy requirements, immature male $A$. fraterculus may also consume less food. Females will require more protein after their first mating to sustain subsequent ovarian cycles, and males more carbohydrate to recover the energy spent mainly in calling activity, which may last up to seven hours.

Salles (1993b) found that the highest percentage of adult $A$. fraterculus caught in traps using food as attractant occurred from the middle to the end of the afternoon. Malo \& Zapien (1994) found that the highest captures of adult $A$. obliqua and A. ludens in traps baited with torula yeast and borax occurred mainly between 14:00 $\mathrm{h}$ and 16:00 h. However, the results obtained in the laboratory cannot be directly correlated with those obtained in the field. In the laboratory, the flies were uniform with regard to age, sexual maturity, and kept in a single cage under constant temperature. Thus, a degree of artificiality remains.

Only mated females were seen laying eggs. They dragged their ovipositors across the fruit surface after egg-laying, probably depositing an oviposition-deterring pheromone (ODP) or 
a host-marking pheromone (HMP) (Prokopy et al. 1982). Papaj \& Aluja (1993) found that in $A$. ludens the HMP was deterrent to female before they started to lay eggs, but it stimulated continued deposition of host-marking pheromone after oviposition. They concluded that when ovipositing female A. ludens are not able to find fruits free of ODP, they will exploit infested ones, rather than die without laying eggs. The territorial behavior of ovipositing female $A$. fraterculus may also be important in partitioning available food resources. Nevertheless, in cages with large numbers of mated females, and only one artificial fruit, several females could be seen ovipositing simultaneously.

Male A. fraterculus started to display courtship behavior at the beginning of the dawn period when they were 5 days old. At 5 days the calling activity lasted for about one hour. It increased gradually to nearly seven hours by the age of 10 days, when they reached complete sexual maturity, being capable of complete expansion of the abdominal pleura when calling. In A. suspensa, the development of the male salivary glands is closely correlated with onset of sexual behavior and pheromone release behavior (Nation 1974). Nation (1981) has also reported that, in male A. fraterculus, the complete development of the salivary glands is reached at 10 days. Thus, the growth of the salivary glands in male $A$. fraterculus also has a close relationship with sexual maturation and pheromone release behavior.

Females A. fraterculus did not copulate before they reached the age of 11 days. Rejection behavior by the female has been reported for other species of fruit fly. In Drosophila melanogaste L., virgin females rejected the male by kicking and flicking, whereas fertilized females used predominantly ovipositor extrusion (Connolly \& Cook 1973). Although 54\% of the virgin mature female $A$. fraterculus copulated on the day they were paired with virgin males of the same age, the females rejected about $71 \%$ of the copulation attempts. Surprisingly, the number of times that a male tried to copulate with another male was almost as many as the observed for males trying to copulate with females. This observation could suggest that calling males are not able to distinguish males from the females.

Males sometimes defended territories moving over the cage while performing behavior such as wing-waving, wing-fanning and rotation of the body. Males also could be seen calling in isolation, and extending their probosces while facing another male. This behavior has been described by Burk (1991) as the most characteristic manifestation of male aggressiveness in Anastrepha. The male's body is tightly pressed to the substrate and stretched to full length, the wings are tightly pressed against the side of the body, and the proboscis extended forward facing the intruder.

Fecundity was not measured in this study, but the efficiency of sperm transference after first mating was $100 \%$. Female A. fraterculus seem to require more than 30 min of mating to supply all spermathecae with sperm, however for more precise discussion, it is necessary to describe quantitatively the amount of sperm transferred as a function of copulation duration.

\section{Acknowledgments}

We gratefully acknowledge financial support from the Conselho Nacional de Desenvolvimento Científico e Tecnológico (CNPq/RHAE-Brazil), grant no. 260087/ 90.4, Dr Luiz A. B. Salles from CPACT/ EMBRAPA for providing pupae of $A$. fraterculus, and Dr Jennifer J. Knapp for her useful comments. This work was carried out under MAFF licence no. PHF 1157/705/83 issued under the Import and Export (Plant Health) (Great Britain) Order 1908 and the Plant Pests (Great Britain) Order 1980.

\section{References Cited}

Aluja, M., M. Cabrera \& J. Hendrichs. 1983. General behavior and interactions between Anastrepha ludens and A. obliqua under seminatural conditions. I. 
lekking behavior and male territoriality, p. 122-133. In: R. Cavalloro (ed.). Fruit flies of economic importance. A.A. Balkema, Rotterdam.

Aluja, M. \& A. Birke. 1993. Habitat use by adults of Anastrepha obliqua (Diptera: Tephritidae) in a mixed mango and tropical plum orchard. Ann. Entomol. Soc. Am. 86: 799-812.

Aluja, M., I. Jácome, A. Birke, N. Lozada \& G. Quintero. 1993. Basic patterns of behavior in wild Anastrepha striata (Diptera: Tephritidae) flies under fieldcage conditions. Ann. Entomol. Soc. Am. 86: 776-793.

Baker, A.C., W.E. Stone, C.C. Plummer \& M.A. Mcphail. 1944. A review of studies on the mexican fruit fly and related mexican species. USDA Misc. Publ. 531: 1-155.

Browne, L.B. 1993. Physiologically induced changes in resource-oriented behaviour. Annu. Rev. Entomol. 38: 1-25.

Burk, T. 1983. Behavioural ecology of mating in the caribbean fruit fly, Anastrepha suspensa (Loew) (Diptera: Tephritidae). Fla. Entomol. 66: 330-334.

Burk, T. 1991. Sex in leks: an overview of sexual behavior in Anastrepha fruit flies, p. 177-189. In Kawasaki, K., O. Iwahashi \& K.Y. Kaneshiro (eds.). Proc. Inter. Symp. Biol. Control of Fruit Flies. Ginowan, Okinawa, Japan.

Connolly, K.J. \& R.M. Cook. 1973. Rejection responses by female Drosophila melanogaster: their ontogeny, causality, and effects upon the behaviour of the courting male. Behaviour 44: 142166.

Dodson, G.N. 1982. Mating and territoriality in wild Anastrepha suspensa (Diptera:
Tephritidae) in field cages. J. Ga. Entomol. Soc. 17: 189-200.

Lima, I.S., P.E. Howse \& L.A.B. Salles. 1994. Reproductive behaviour of the South American fruit fly Anastrepha fraterculus (Diptera: Tephritidae): laboratory and field studies. Physiol. Entomol. 19: 271-277.

Malavasi, A., J.S. Morgante \& R.J. Prokopy. 1983. Distribution and activities of Anastrepha fraterculus (Diptera: Tephritidae) flies on host and non-host trees. Ann. Entomol. Soc. Am. 76: 286-292.

Malo, E.A. \& G.I. Zapien. 1994. McPhail trap captures of Anastrepha obliqua and Anastrepha ludens (Diptera: Tephritidae) in relation to time of day. Fla. Entomol. 77: 290-294.

Morgante, J.S., A. Malavasi \& R.J. Prokopy. 1983. Mating behaviour of wild Anastrepha fraterculus (Diptera: Tephritidae) on a caged host tree. Fla. Entomol. 66: 234-241.

Morgante, J.S., D. Selivon, V.N. Solferini \& S.R. Matioli. 1993. Evolutionary patterns in specialist and generalist species of Anastrepha, p. 15-20. In M. Aluja and P. Liedo (eds.). Fruit flies: biology and management. SpringerVerlag, New York.

Nation, J.L. 1974. The structure and development of two sex specific glands in male Caribbean fruit flies. Ann. Entomol. Soc. Am. 67: 731-734.

Nation, J.L. 1981. Sex-specific glands in tephritid fruit flies of the genera Anastrepha, Ceratitis, Dacus and Rhagoletis (Diptera: Tephritidae). Int. J. Insect. Morphol. Embryol. 10: 121-129.

Papaj, D.R. \& M. Aluja. 1993. Temporal 
dynamics of host-marking in the tropical tephritid fly, Anastrepha ludens. Physiol. Entomol. 18: 279-284.

Prokopy, R.J., A. Malavasi \& J.S. Morgante. 1982. Oviposition deterring pheromone in Anastrepha fraterculus. J. Chem. Ecol. 8: 763-771.

Prokopy, R.J. \& B.D. Roitberg. 1984. Foraging behaviour of true fruit flies. Am. Scientist 72: 41-49.

Salles, L.A.B. 1992. Metodologia de criação de Anastrepha fraterculus (Wied., 1830) Diptera: Tephritidae) em dieta artificial em laboratório. An. Soc. Entomol. Brasil. 21: 479-486.
Salles, L.A.B. 1993a. Influência do fotoperíodo no desenvolvimento de Anastrepha fraterculus (Wied., 1830) (Diptera: Tephritidae). An. Soc. Entomol. Brasil. 22: 47-55.

Salles, L.A.B. 1993b. Horário de captura de Anastrepha fraterculus (Wied., 1830) (Diptera: Tephritidae) em pomar de pessegueiro. An. Soc. Entomol. Brasil. 22: 105-108.

Wigglesworth, V.B. 1984. Insect physiology. Chapman and Hall, New York, 191 p.

Received 17/IV/96. Accepted 09/VII/97. 